\title{
Association between Schistosoma mansoni infection and access to improved water and sanitation facilities in Mwea, Kirinyaga County, Kenya
}

Paul M. Gichuki ${ }^{1,2^{*}}$, Stella Kepha ${ }^{3,4}$, Damaris Mulewa ${ }^{1}$, Janet Masaku', Celestine Kwoba ${ }^{5}$, Gabriel Mbugua ${ }^{2}$, Humphrey D. Mazigo ${ }^{6}$ and Charles Mwandawiro'

\begin{abstract}
Background: Schistosomiasis remains a public health problem in Central Kenya despite concerted control efforts. Access to improved water and sanitation has been emphasized as important control measures. Few studies have assessed the association between access to improved water sources and sanitation facilities with Schistosoma mansoni infection in different environmental settings. This study assessed the association between S. mansoni infection and household access to improved water sources and sanitation facilities in Mwea, Kirinyaga County, Kenya.

Methods: A cross sectional study was conducted between the months of August and October 2017. A total of 905 household heads from seven villages were interviewed and their stool samples screened for S. mansoni using the Kato Katz technique. Comparisons of demographic factors by S. mansoni infection were tested for significance using the chisquare test (X2) or the Fisher exact test for categorical variables. Variables associated with $\mathrm{S}$. mansoni infection were analyzed using univariable analysis and the strength of the association measured as odds ratio (OR) using mixed effects logistic regression at $95 \% \mathrm{Cl}$, with values considered significant at $p<0.05$.

Results: The overall prevalence of S. mansoni was, 23.1\% (95\% Cl: 20.5-26.0\%), with majority of the infections being of light intensity. Rurumi village had the highest prevalence at $33.3 \%$, with Kirogo village having the least prevalence at 7.0\%. Majority (84.1\%) of the households lacked access to improved water sources but had access to improved sanitation facilities (75\%). Households with access to piped water had the lowest S. mansoni infections. However, there was no significant association between S. mansoni infections with either the main source of water in the household (Odds Ratio $(\mathrm{OR})=0.782$ (95\% Cl: $0.497-1.229) p=0.285$ or sanitation facilities $(\mathrm{OR}=1.018$ (95\% Cl: $0.705-1.469) p=$ 0.926.

Conclusion: Our study suggests that S. mansoni is still a public health problem among all age groups in Mwea irrigation scheme, Kirinyaga County, Central Kenya. Majority of the households lacks access to improved water sources but have access to improved sanitation facilities. This study recommends initiatives to ensure adequate provision of improved water sources, and the inclusion of the adult community in preventive chemotherapy programs.
\end{abstract}

Keywords: Schistosoma mansoni, Water, Sanitation, Improved, Unimproved, Kenya

\footnotetext{
* Correspondence: paulmgichuki@gmail.com; pgichuki@kemri.org

${ }^{1}$ Eastern and Southern Africa Center for International Parasite Control

(ESACIPAC), Kenya Medical Research Institute (KEMRI), P.O BOX 54840-00200,

Nairobi, Kenya

${ }^{2}$ School of Health Sciences, Meru University of Science and Technology, P.O

BOX 972-60200, Meru, Kenya

Full list of author information is available at the end of the article
}

(c) The Author(s). 2019 Open Access This article is distributed under the terms of the Creative Commons Attribution 4.0 International License (http://creativecommons.org/licenses/by/4.0/), which permits unrestricted use, distribution, and reproduction in any medium, provided you give appropriate credit to the original author(s) and the source, provide a link to the Creative Commons license, and indicate if changes were made. The Creative Commons Public Domain Dedication waiver (http://creativecommons.org/publicdomain/zero/1.0/) applies to the data made available in this article, unless otherwise stated. 


\section{Background}

Schistosomiasis is a parasitic disease caused by a trematode worm of the genius Schistosoma [1]. There are two types of schistosomiasis, intestinal and urinary. Intestinal schistosomiasis is caused by Schistosoma mansoni and Schistosoma japonicum where parasite eggs are released in faeces while urinary schistosomiasis is caused by Schistosoma haematobium, and parasite eggs are released in the urine [1]. Schistosoma mansoni, transmitted by Biomphalaria snails and Schistosoma haematobium, transmitted by Bulinus snails are the most prevalent Schistosoma species [2]. According to the Global burden of disease report of 2013, more than 290 million people worldwide are estimated to be infected with schistosomiasis, about 600-780 million are at risk of infection, with morbidity due to these infections resulting to an estimated 2.8 million disability adjusted life years (DALYs) [2]. Schistosomiasis is endemic in more than 78 countries, with more than $90 \%$ of the infections occurring in sub- Saharan Africa [3].

In Kenya, approximately six million people have schistosomiasis and an additional fifteen million are at risk of infection [4]. Two species are predominant in Kenya, Schistosoma haematobium and, Schistosoma mansoni [5]. Recent findings reported prevalence of $2.1 \%$ for Schistosoma mansoni, and $14.8 \%$ for Schistosoma haematobium among school going children [6]. The distribution of Schistosomiasis in Kenya is such that Schistosoma haematobium is found mainly around the coast regions, some parts of Lake Victoria and Kano plains in Western Kenya [7], while Schistosoma mansoni occurs mainly in the Western parts of the country [8], and some parts of Central Kenya [9].

A school based schistosomiasis and soil transmitted helminths control programme was initiated in the year 2004 through collaboration between Kenya Medical Research Institute (KEMRI) and Japan International Corporation Agency (JICA). The programme entailed mass drug administration (MDA) of preventive chemotherapy to all school age children in Mwea, Kirinyaga County [10]. The preventive chemotherapy included a single dose of $40 \mathrm{mg} / \mathrm{kg}$ of Praziquantel administered using the tablet dose pole to determine the number of tablets to be taken by a child, and Albendazole as a single dose of $400 \mathrm{mg}$ [11]. The programme was implemented until the year 2008, after which MDA was taken over by the Kenya National School based deworming programme.

Schistosomiasis contributes significantly to lower social economic conditions in areas where it is endemic and causes a great deal of disability thus reducing the work performance among the infected individuals. However, mortality associated with these infections is low [12]. Schistosomiasis infections have been shown to increase the susceptibility to or severity of co-infecting pathogens [1], and as a result the disease has been targeted for control and eventual elimination by the World Health Organization (WHO) [13].

Like many other endemic countries, the control of schistosomiasis is through mass drug administration (MDA) using the drug of choice Praziquantel [13]. Although chemotherapy is cost-effective [14] and reduces schistosome infections in human hosts [15], it has a limitation in that it does not kill immature worms [16] and has low impact on transmission [17]. This intervention is often delivered through school based deworming programme (SBDP) and offers many benefits to the treated children [18].

Recently, there has been global advocacy geared towards schistosomiasis transmission interruption, with a call in the year 2012 by the World Health Assembly (WHA) resolution 65.21, on countries to intensify control and initiate elimination campaigns [19]. Water, sanitation and hygiene education (WASH) have been emphasized as a component of an integrated control and elimination strategy in the WHA resolution on the bases that they should reduce schistosomiasis transmission by reducing human water contact [20]. WASH has been acknowledged in WHO prevention and control guidelines, which advices the inclusion of the same in helminth control programs [21].

The provision of access to safe drinking water, hygiene and sanitation, which has also been classified as the "forgotten foundations of health" [22, 23], though essential in the control of schistosomiasis, is inadequate in large parts of low and middle-income countries where schistosomiasis is endemic $[1,24]$. WASH interventions have the potential to reduce the environmental exposure to infected schistosome eggs and larvae and thus reduce transmission of the disease ensuring a long term improvement in people's wellbeing $[25,26]$.

Even though the important role of WASH has been recognized and advocated for in the World Health Assembly (WHA) resolutions on schistosomiasis [27], WASH has not been incorporated in disease specific control programs. For this to happen, there is need for data on the levels of community access to clean water, sanitation and hygiene and how each aspect of WASH associates with schistosomiasis infection in different endemic settings. This will help us understand which specific WASH intervention is most effective in reducing exposure to infection in what environmental setting. Several studies have reported on the effects of WASH on NTDs especially STHs [28-33], however, little evidence exists to inform policy decisions about the importance of including WASH as part of schistosomiasis control. Therefore, the aim of this study was to describe the association between $S$. mansoni infection and household access to improved water sources and sanitation facilities in Kirinyaga County, central Kenya. 


\section{Methods}

\section{Study area}

The present study was conducted in two different Sub Counties of Kirinyaga County. The Sub Counties included Mwea East and West. Kirinyaga County lies between $1158 \mathrm{M}$ and $5380 \mathrm{M}$ above sea level in the South and at the Peak of Mount Kenya respectively, with a mean annual rainfall ranging between 1200 and 1600 $\mathrm{mm}$ per year. Covering an area of $1478.1 \mathrm{~km}^{2}$, the County is located about $100 \mathrm{kms}$ north east of Nairobi. Figures from the 2009 census indicate that the County had an estimated total population of 528,054 persons, with an annual growth rate of $1.5 \%$. The population was projected to be 593,379 in the year 2017 [34]. There were an estimated 154, 220 households in the county. The two Sub Counties are home to the giant Mwea irrigation scheme where several water canals crisscross the area supplying irrigation water to the farms and villages respectively. The main socio-economic activities include rice and horticultural farming. Generally, Mwea East and West Sub Counties are endemic for S. mansoni [9, $35,36]$. However, data on community access to improved water and sanitation is lacking.

\section{Study population and selection criteria}

In Mwea West Sub County, there were two locations both of which were located within the irrigation scheme (Thiba and Mutithi); while in Mwea East there were a total of five locations. These included Gathigiriri, Tebere, Murinduko, Nyangati and Kangai. Tebere and Gathigiriri locations were located within the Mwea irrigation scheme. Tebere and Gathigiriri locations in Mwea East and Thiba and Mutithi in Mwea West were included in the study since they were located within the irrigation scheme. Tebere and Thiba locations from Mwea East and West respectively were then sampled randomly and included in the study. Tebere location had a total of six villages which included Kamucege, Gathigiriri, Block, Kiarukungu, Mahigaini and Kirogo, while Thiba had eight villages including Mbui Njeru, Maendeleo, Gakungu, Rurumi, Thiba, Karima, Kiratina and Kasarani. Four and three villages from Thiba and Tebere locations respectively were selected and included in the study (Fig. 1). The study villages are shown in Fig. 2.

\section{Study design and sample size determination}

This was a cross sectional study carried out between the months of August and October 2017. The study used prevalence of $26 \%$ for Schistosoma mansoni derived from a recent study in the area [35], level of significance and an error margin of 0.05 , and standard deviation at $95 \%$ CI (1.96) to calculate the sample size [37]. A sample size of 432 per sub County was calculated, and multiplied by two since the study was covering two sub Counties to

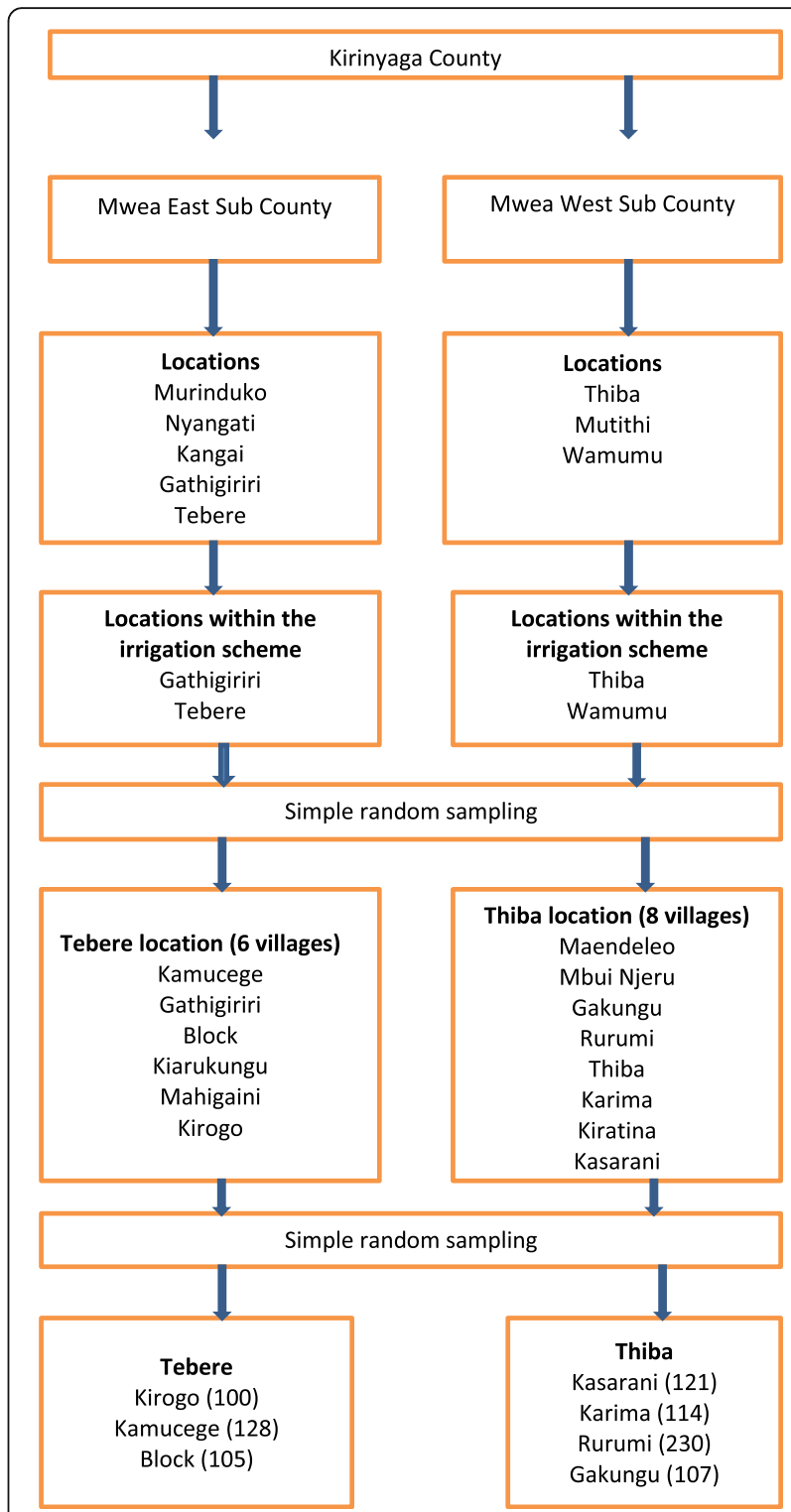

Fig. 1 Flow diagram showing selection of study villages

give a minimum sample size of 864 which was then adjusted to 905 to cater for refusals and incomplete data.

Lists of all households per each village were obtained from the village Community Health Workers (CHW). Using probability proportional to size sampling and the total number of households per village, each village was allocated a minimum number of households to be sampled from the total study sample size. In each village, the first household to be sampled was identified by the study team and systematic random sampling used to locate every third household during the survey. In each household sampled, the head or a representative of the sampled household was interviewed. The study team held meetings with the leadership at the County and Sub County level, the local administration and village 


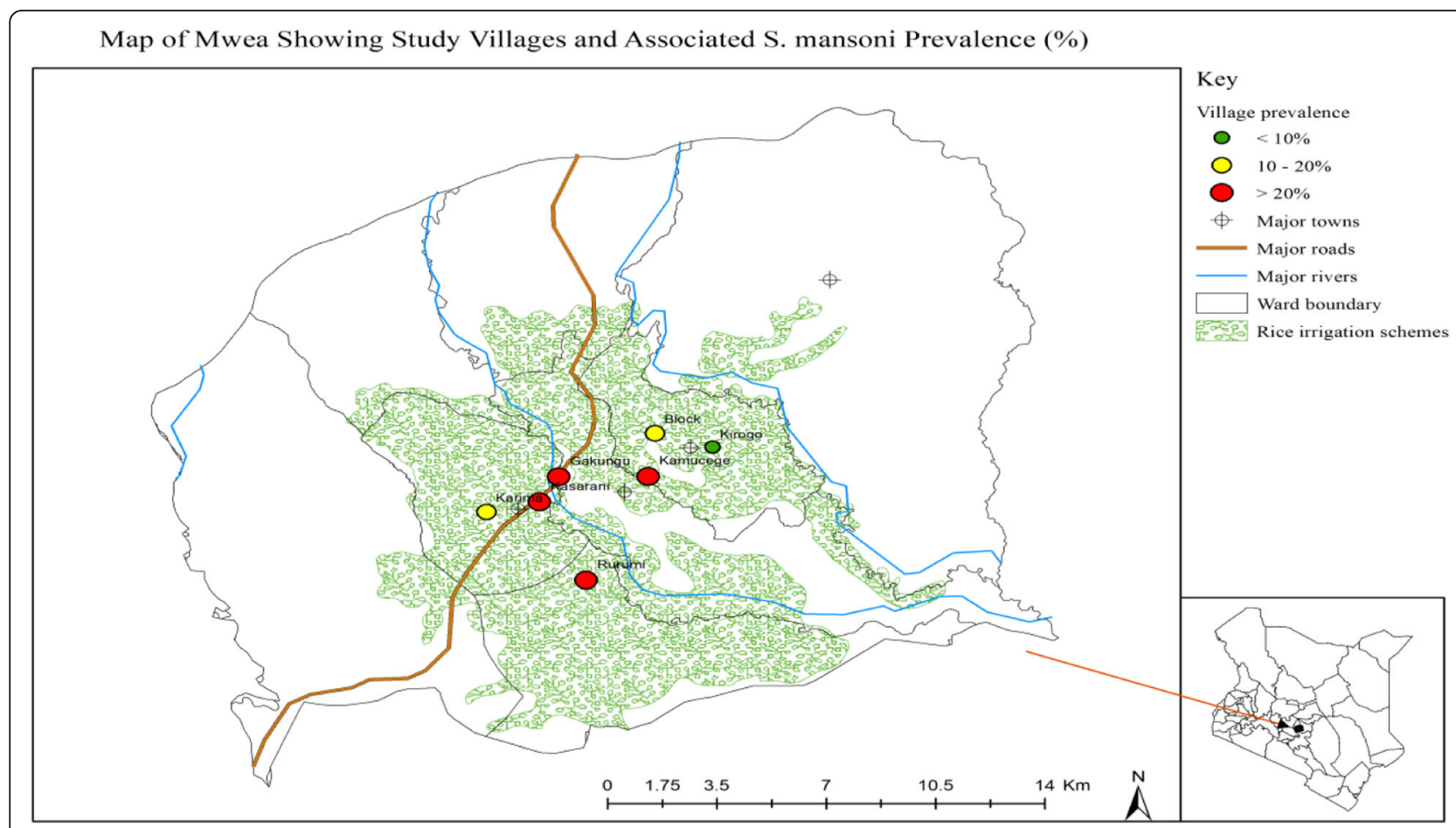

Fig. 2 Map of Mwea, showing the study villages and associated S. mansoni prevalence

members in all the seven study villages prior to the start of data collection to explain to them the purpose of the study and seek their consent. Each participating household head gave individual written consent before the survey.

\section{Questionnaire administration}

A structured questionnaire developed in English and translated to the local language (kikuyu) was administered to the household heads in selected households. The questionnaire included sections on social demographic indicators such as age, sex, marital status, religion, education, occupation, and the assessment of water and sanitation. The section on water and sanitation was developed based on the definitions by the joint monitoring programme (JMP), of the World Health Organization (WHO) and the United Nations Children Fund (UNICEF), for water and sanitation [38]. Improved sanitation facilities was assessed in households that had flush toilet, a piped sewer system, a septic tank, flush/ pour to a pit latrine, ventilated improved pit latrine (VIP), pit latrine with slab and a composting toilet. Unimproved toilet facilities were assessed in households that had flush pour to elsewhere, pit latrine without slab, bucket, hanging toilet/ latrine or no facility at all. Improved water source were assessed in households which had access to piped water into dwelling, piped water to yard/ plot, public tap or stand pipe, tube well or borehole, protected dug well, protected spring, bottled water and rain water, while Unimproved water source included unprotected spring, unprotected dug well, cart with small tank, tanker-truck and surface water. Surface water included rivers, dams, lakes, ponds, streams, canals and irrigation channels. Additional information in this section included time taken to the water source and whether the household head was satisfied with the source. Presence of sanitation facility and water source in the household, whether there were faeces on the toilet floor, and whether or not the toilet was in use was observed by physically visiting the facility. Information on toilet sharing was also collected (Additional file 1).

\section{Parasitological screening for S. mansoni}

Household heads or their adult representatives were asked to provide a stool sample. A clean screw capped, well labeled plastic container with scoop was provided with instructions on how to collect a stool sample. Those who were not able to provide a stool sample were visited the next day until they got the sample. The samples were collected the same day or the following morning and taken to Kimbimbi Sub County hospital laboratories for analysis. Samples that could not be processed the same day were stored at $4{ }^{\circ} \mathrm{C}$. In the laboratory, Kato Katz techniques was used in sample processing where each sample was prepared in duplicate smears of $41.7 \mathrm{mg}$ [39]. A random sample of $10 \%$ of all the positive and negative slides read each day were randomly 
Table 1 Household demographic factors aggregated by villages

\begin{tabular}{|c|c|c|c|c|c|c|c|c|}
\hline Characteristic & $\begin{array}{l}\text { Karima } \\
\mathrm{N}(\%)\end{array}$ & $\begin{array}{l}\text { Rurumi } \\
\text { N (\%) }\end{array}$ & $\begin{array}{l}\text { Kasarani } \\
\mathrm{N}(\%)\end{array}$ & $\begin{array}{l}\text { Kirogo } \\
N(\%)\end{array}$ & $\begin{array}{l}\text { Kamucege } \\
\mathrm{N}(\%)\end{array}$ & $\begin{array}{l}\text { Block } \\
\text { N (\%) }\end{array}$ & $\begin{array}{l}\text { Gakungu } \\
\text { N (\%) }\end{array}$ & Total \\
\hline \multicolumn{9}{|l|}{ Sex } \\
\hline Male & $34(29.8)$ & $106(46.1)$ & $22(18.1)$ & $25(25.0)$ & $33(25.8)$ & $28(26.7)$ & $19(17.8)$ & $267(29.5)$ \\
\hline Female & $80(70.2)$ & $124(53.9)$ & 99 (81.9) & $75(75.0)$ & $95(74.2)$ & 77 (73.3) & 88 (82.2) & $638(70.5)$ \\
\hline \multicolumn{9}{|l|}{ Age (years) } \\
\hline$\leq 25$ & $15(13.2)$ & $21(9.1)$ & $9(7.4)$ & $6(6.0)$ & $12(9.4)$ & $11(10.5)$ & $15(14.0)$ & $89(9.8)$ \\
\hline $26-35$ & $22(19.3)$ & $69(30.0)$ & 37 (30.6) & $25(25.0)$ & $30(23.4)$ & $37(35.2)$ & $41(38.8)$ & $261(28.8)$ \\
\hline $36-45$ & $27(23.7)$ & $72(31.3)$ & 39 (32.2) & $29(29.0)$ & 37 (28.9) & $34(32.4)$ & $33(30.9)$ & $271(30.0)$ \\
\hline $46-55$ & $21(18.4)$ & $30(13.0)$ & $30(24.8)$ & $24(24.0)$ & $23(18.0)$ & $8(7.6)$ & $14(13.1)$ & 150 (16.6) \\
\hline$>55$ & $29(25.4)$ & 38 (16.6) & $6(5.0)$ & $16(16.0)$ & $26(20.3)$ & $15(14.3)$ & $4(3.7)$ & $134(14.8)$ \\
\hline \multicolumn{9}{|l|}{ Marital status } \\
\hline Married & $97(85.1)$ & $179(77.8)$ & $105(86.8)$ & $89(89.0)$ & $109(85.2)$ & $83(79.0)$ & $94(87.9)$ & 756 (83.5) \\
\hline Single/ Window(wer)/ Divorced & $17(14.9)$ & $51(22.2)$ & $16(13.2)$ & $11(11.0)$ & $19(14.8)$ & $22(21.0)$ & $13(12.1)$ & $149(16.5)$ \\
\hline \multicolumn{9}{|l|}{ Religion } \\
\hline Christian & $106(93)$ & $220(95.7)$ & $116(95.8)$ & $95(95.0)$ & $117(91.4)$ & $100(95.2)$ & $106(99.1)$ & $860(95.0)$ \\
\hline Others & $8(7.0)$ & $10(4.3)$ & $5(4.2)$ & $5(5.0)$ & $11(8.6)$ & $5(4.8)$ & $1(0.9)$ & $45(5.0)$ \\
\hline \multicolumn{9}{|l|}{ Education } \\
\hline No formal education & $20(17.5)$ & $12(5.2)$ & $5(4.1)$ & $7(7.0)$ & $16(12.5)$ & $10(9.5)$ & $2(1.9)$ & $72(7.6)$ \\
\hline Primary (Incomplete) & $31(27.2)$ & $72(31.3)$ & $38(31.4)$ & $26(26.0)$ & $42(32.8)$ & $37(35.2)$ & $35(32.7)$ & $280(20.9)$ \\
\hline Primary (Complete) & $41(36.0)$ & $107(46.5)$ & $45(37.2)$ & $48(48.0)$ & $47(36.8)$ & $38(36.2)$ & $41(38.3)$ & $370(40.9)$ \\
\hline Secondary Incomplete) & $20(17.5)$ & $31(13.5)$ & $26(21.5)$ & $16(16.0)$ & $20(15.6)$ & $14(13.3)$ & $23(21.5)$ & $152(16.8)$ \\
\hline Secondary and post-secondary & $2(1.8)$ & $8(3.5)$ & $7(5.8)$ & $3(3.0)$ & $3(2.3)$ & $6(5.8)$ & $6(5.6)$ & $31(13.8)$ \\
\hline \multicolumn{9}{|l|}{ Occupation } \\
\hline Business & $8(7.0)$ & $24(10.4)$ & $26(21.5)$ & $13(13.0)$ & $15(11.7)$ & $17(16.2)$ & $20(18.7)$ & $123(13.6)$ \\
\hline Casual labourers & $9(7.9)$ & $47(20.4)$ & $18(14.9)$ & $10(10.0)$ & $19(14.8)$ & $20(19.0)$ & $23(21.5)$ & $146(16.1)$ \\
\hline Others & $8(7.0)$ & $13(5.7)$ & $18(14.9)$ & $1(1.0)$ & $4(3.2)$ & $6(5.8)$ & $11(10.3)$ & $61(6.7)$ \\
\hline Farmer & 89 (78.1) & $146(63.5)$ & 59 (48.7) & $76(76.0)$ & $90(70.3)$ & $62(59)$ & 53 (49.5) & 575 (63.6) \\
\hline
\end{tabular}

reexamined by a third experienced laboratory technologists to ensure quality work.

\section{Data analysis}

Household data collected was entered and stored in an excel spreadsheet and counter checked for accuracy. Parasitology data was entered in the laboratory parasitology result forms and then entered in the excel spreadsheet. Data was analyzed using STATA version 14.0 (Stata Corporation, College Station, TX, USA). Presence of $S$. mansoni egg across the duplicate slides indicated infection while the arithmetic mean of eggs per gram (epg) of faeces across the duplicate slides expressed the intensity of the infection. The infection intensity was categorized according to the WHO classifications for $S$. mansoni (0) negative, (1-99) light, (100-399) moderate and (>400) heavy [40]. The prevalence of S. mansoni was calculated by age group, gender and village of residence. Comparisons of demographic factors by $S$. mansoni infection were tested for significance using the chi-square test $(x 2)$ or the Fisher exact test for categorical variables. Factors associated with $S$. mansoni infection were analyzed using univariable analysis and the strength of the association measured as odds ratio (OR) using mixed effects logistic regression at $95 \% \mathrm{CI}$, with values considered significant at $p<0.05$.

\section{Ethical considerations}

Prior to the implementation of the study, ethical approvals were sought from the Scientific and Ethical Review Unit (SERU) of the Kenya Medical Research Institute (KEMRI), number (KEMRI/SERU/ESACIPAC/ 007/3326) and Meru University of Science and Technology Institutional Research Ethics Review Committee (MIRERC), number (MIRERC/001/2017), and the Health Management Team of Kirinyaga County. All the household heads participating in the study signed a written informed consent which had been translated into the local 
Table 2 Household access to water sources and sanitation facilities aggregated by villages $(N=905)$

\begin{tabular}{|c|c|c|c|c|c|c|c|c|}
\hline Characteristic & $\begin{array}{l}\text { Karima } \\
\mathrm{N}(\%)\end{array}$ & $\begin{array}{l}\text { Rurumi } \\
\mathrm{N}(\%)\end{array}$ & $\begin{array}{l}\text { Kasarani } \\
\mathrm{N}(\%)\end{array}$ & $\begin{array}{l}\text { Kirogo } \\
N(\%)\end{array}$ & $\begin{array}{l}\text { Kamucege } \\
\mathrm{N}(\%)\end{array}$ & $\begin{array}{l}\text { Block } \\
\text { N (\%) }\end{array}$ & $\begin{array}{l}\text { Gakungu } \\
\text { N (\%) }\end{array}$ & Total \\
\hline \multicolumn{9}{|l|}{ Source of water } \\
\hline Piped water & $0(0)$ & $7(3.0)$ & $19(15.7)$ & $9(9.0)$ & $0(0)$ & $0(0)$ & $13(12.1)$ & $48(5.3)$ \\
\hline Borehole & $0(0)$ & $0(0)$ & $0(0)$ & $49(49.0)$ & $0(0)$ & $0(0)$ & $0(0)$ & $49(5.4)$ \\
\hline Protected dug well & $0(0)$ & $0(0)$ & $0(0)$ & $0(0)$ & $0(0)$ & $10(9.5)$ & $6(4.7)$ & $6(0.7)$ \\
\hline Rainwater collection & $2(1.8)$ & $21(9.1)$ & $2(1.7)$ & $1(1.0)$ & $0(0)$ & $2(1.9)$ & $4(3.7)$ & $32(3.5)$ \\
\hline Other sources & $0(0)$ & $0(0)$ & $5(4.1)$ & $0(0)$ & $0(0)$ & $0(0)$ & $0(0)$ & $5(0.6)$ \\
\hline Surface water/ unprotected dug well & 112(98.2) & $202(87.2)$ & $95(78.5)$ & $41(41.0)$ & $128(100)$ & $103(98.1)$ & $84(78.5)$ & $765(84.5)$ \\
\hline \multicolumn{9}{|l|}{ Time taken to fetch water } \\
\hline On premises & $0(0)$ & $59(25.7)$ & $93(76.9)$ & $49(49.0)$ & $19(14.8)$ & $23(21.9)$ & $54(50.5)$ & $297(32.8)$ \\
\hline Less than thirty minutes & $111(97.4)$ & $147(63.9)$ & $28(23.1)$ & $51(51.0)$ & $109(85.2)$ & $82(78.1)$ & $50(46.7)$ & $578(63.9)$ \\
\hline More than thirty minutes & $3(2.6)$ & $24(10.4)$ & $0(0)$ & $0(0)$ & $0(0)$ & $0(0)$ & $3(2.8)$ & $30(3.3)$ \\
\hline \multicolumn{9}{|l|}{ Sanitation facility } \\
\hline VIP/Simple latrine with floor slab & $98(86.0)$ & $149(64.8)$ & $104(85.9)$ & $91(91.0)$ & $87(68.0)$ & $60(57.1)$ & 89 (83.2) & $678(74.8)$ \\
\hline Pit latrine without floor slab & $16(14)$ & $62(27.0)$ & $12(9.9)$ & $7(7.0)$ & $38(29.7)$ & $45(42.9)$ & $18(16.8)$ & $198(21.9)$ \\
\hline Other & $0(0)$ & $8(3.5)$ & $5(4.2)$ & $2(2.0)$ & $0(0)$ & $0(0)$ & $0(0)$ & $15(1.7$ \\
\hline No facility & $0(0)$ & $11(4.7)$ & $0(0)$ & $0(0)$ & $3(2.3)$ & $0(0)$ & $0(0)$ & $14(1.6)$ \\
\hline \multicolumn{9}{|l|}{ Reported sanitation access } \\
\hline Shared & $25(78.1)$ & $45(20.5)$ & $30(24.8)$ & $25(25.0)$ & $33(25.8)$ & $18(17.1)$ & $18(16.8)$ & $194(21.7)$ \\
\hline Not shared & 89 (21.9) & $174(79.5)$ & $91(75.2)$ & $75(75.0)$ & $95(74.2)$ & $87(82.9)$ & $89(83.2)$ & $700(78.3)$ \\
\hline \multicolumn{9}{|l|}{ Toilet in use } \\
\hline Yes & $114(100)$ & $226(98.3)$ & $120(99.2)$ & $100(100)$ & $0(0)$ & $103(98.1)$ & $107(100)$ & $898(99.2)$ \\
\hline No & $0(0)$ & $4(1.7)$ & $1(0.8)$ & $0(0)$ & $0(0)$ & $2(1.9)$ & $0(0)$ & $7(0.8)$ \\
\hline \multicolumn{9}{|l|}{ Visible faeces on the edges } \\
\hline Yes & $17(14.9)$ & $52(27.4)$ & $10(8.3)$ & $21(21.0)$ & $37(28.9)$ & $31(29.5)$ & $20(18.7)$ & $188(21.0)$ \\
\hline No & $97(85.1)$ & $167(72.6)$ & $111(91.7)$ & $79(79.0)$ & $91(71.1)$ & $74(70.5)$ & $87(81.3)$ & $706(79.0)$ \\
\hline \multicolumn{9}{|l|}{ Household has child (ren) under 3 years } \\
\hline Yes & $17(14.9)$ & $74(32.2)$ & $37(30.6)$ & $28(28.0)$ & $26(20.3)$ & $19(18.1)$ & $47(43.9)$ & $248(27.4)$ \\
\hline No & $97(85.1)$ & $156(67.8)$ & $84(69.4)$ & $72(72.0)$ & 102(79.7) & $86(81.9)$ & $60(56.1)$ & $657(72.6)$ \\
\hline \multicolumn{9}{|l|}{ Disposal of feaces for under 3 years } \\
\hline Child used toilet/ latrine & $1(6.0)$ & $15(20.3)$ & $12(32.4)$ & $8(28.6)$ & $13(50)$ & $13(68.4)$ & $16(30.1)$ & 78(31.4) \\
\hline Other & $16(94.0)$ & $55(74.3)$ & $24(64.9)$ & $17(60.7)$ & $12(46.2)$ & $0(0)$ & $30(63.8)$ & $154(62.1)$ \\
\hline Put/ rinsed in toilet/ latrine & $0(0)$ & $4(5.4)$ & $1(0.7)$ & $3(10.7)$ & $1(3.8)$ & $6(31.6)$ & $1(6.1)$ & $16(6.5)$ \\
\hline
\end{tabular}

$\mathrm{N}=905$ Karima $\mathrm{N}=114$, Rurumi $\mathrm{N}=230$, Kasarani $\mathrm{N}=121$, Kirogo $\mathrm{N}=100$, Kamucege $\mathrm{N}=128$, Block $\mathrm{N}=105, \mathrm{Gakungu}=107$

dialect. Those who could not read or write were asked to have an independent person as a witness who ensured that the study was clearly explained to them and guided them to give a thumb print on the consent form.

\section{Results}

Demographic information of the study participants

Overall, data was collected from a total of 905 household heads who gave a written informed consent, $70.5 \%$ of whom were female. The age of the respondents ranged from 17 to 95 years. Respondents within the age bracket of 36 and 45 years were the majority $30.3 \%$, followed by those in the age bracket of 26 and 35 years at $28.8 \%$. Majority of the respondents were Christians (95.0\%), married $(83.5 \%)$ and farmers $(63.6 \%)$. Those who had no formal education were $7.6 \%$, most of who hailed from Karima village as shown in Table 1.

\section{Household access to improved water and sanitation facilities}

Majority of the households (84.1\%) had access to unimproved water sources mainly from surface water sources such as canals, rivers and streams. Other sources of water included piped water to plot (5.7\%), borehole 
(5.6\%) and rainwater collection (4.0\%). Kasarani village had the highest households with access to piped water (19.0\%), while Kirogo village had the highest access to borehole water at $49.0 \%$. Majority of the households had improved sanitation facilities $(74.9 \%)$, where the most common type was the VIP/simple latrine with concrete floor slab. Pit latrine without floor slab was the most common unimproved type at (21.9\%). Rurumi village had the highest percentage $(4.7 \%)$ of households without a sanitation facility (Table 2).

\section{Prevalence and intensity of $S$. mansoni infections}

The overall prevalence of $S$. mansoni was $23.1 \%$ (95\% CI: 20.5-26.0\%). The highest prevalence was reported in Rurumi village (31.3\%), followed by Kasarani, Gakungu and Kamucege villages (28.1, 25.2 and 23\%) respectively. Kirogo village had the least infection. Compared to Gakungu, residents of Kirogo village had about 78\% lower odds of having $S$. mansoni infection (OR) $0.223(95 \%$ CI $0.092-0.540), p<0.001$ ). The burdens of $S$. mansoni infections were not significantly different in all the other villages. The number of $S$. mansoni eggs observed in the specimens ranged from 12 to 8148 eggs per gram (epg) of faeces. Majority of the S. mansoni infections $(75 \%)$ were of light intensity (Table 3 ).

\section{Association between S. mansoni infection and demographic variables}

Table 4 summarizes the results for the association between S. mansoni infection and household demographic variables. Generally, male participants had the highest infection than female participants, though not statistically significant (26 and $22 \%$ respectively, $p=0.237$ ). Households whose heads were farmers had the highest infection (24\%) as compared to those whose occupation was business (19.8\%) although not statistically significant $p=0.600$. There were no statistical significant associations between S. mansoni infections and participant's other social demographic attributes including education and marital status.

Infection with $S$. mansoni was highest among participants of more than 55 years of age $(26.1 \%)$, followed by the age group 26 to 35 years (25.7\%). The lowest prevalence of $S$. mansoni infections was recorded among study participants of age group 36-45 years (19.3\%). In the age group $\leq 25$ years and $>55$ years, male participants had higher prevalence compared to female participants. In the 26 to 35 years' age group men had lower prevalence of S. mansoni infections compared to women (23 and $32 \%$ respectively) (Fig. 3 ).

\section{Association between S. mansoni infections, water and sanitation variables}

A total of 138 (15.2\%) households had access to improved water sources. Out of these households, 27 (19.6\%) household heads were infected with S. mansoni. Among the various sources of water, participants from households utilizing piped water had the lowest proportion of infections with S. mansoni (13\%). Prevalence of $S$. mansoni infection were 14, 24, 31 and 50\% among the participants who reported that their main source of drinking water was borehole, unprotected dug well/surface water, rainwater collection and protected dug well respectively. Nonetheless, there was no significant association between the main sources of water in households and infection with S. mansoni, (OR $=0.782$ (95\% CI: $0.497-1.229) p=0.285$. Being satisfied with the water supply was a significant predictor of $S$. mansoni infection $(p<0.004)$. Those who reported that they were satisfied with the water supply had $38 \%$ reduction in odds of being found to be infected with $S$. mansoni when assessed against their counterparts whose opinion was on the

Table 3 Prevalence and Intensity of Schistosoma mansoni infections by villages

\begin{tabular}{|c|c|c|c|c|c|c|c|c|}
\hline & $\begin{array}{l}\text { Karima } \\
\mathrm{N}(\%)\end{array}$ & $\begin{array}{l}\text { Rurumi } \\
\text { N (\%) }\end{array}$ & $\begin{array}{l}\text { Kasarani } \\
\mathrm{N}(\%)\end{array}$ & $\begin{array}{l}\text { Kirogo } \\
\mathrm{N}(\%)\end{array}$ & $\begin{array}{l}\text { Kamucege } \\
\mathrm{N}(\%)\end{array}$ & $\begin{array}{l}\text { Block } \\
\mathrm{N}(\%)\end{array}$ & $\begin{array}{l}\text { Gakungu } \\
\mathrm{N}(\%)\end{array}$ & Total \\
\hline \multicolumn{9}{|l|}{ S. mansoni } \\
\hline Positive & 21 & 72 & 34 & 7 & 29 & 19 & 27 & 209 \\
\hline Negative & 93 & 158 & 87 & 93 & 99 & 86 & 80 & 696 \\
\hline Prevalence & 18.4 & 31.3 & 28.1 & 7 & 22.7 & 18.1 & 25.2 & 23.1 \\
\hline OR (95\% Cl) & $\begin{array}{l}0.669(0.351- \\
1.274)\end{array}$ & $\begin{array}{l}1.350(0.805- \\
2.266)\end{array}$ & $\begin{array}{l}1.158(0.642- \\
2.088)\end{array}$ & $\begin{array}{l}0.223(0.092- \\
0.540)\end{array}$ & $\begin{array}{l}0.868(0.476- \\
1.584)\end{array}$ & $\begin{array}{l}0.655(0.338- \\
1.268)\end{array}$ & REF & \\
\hline$P$-value & 0.220 & 0.255 & 0.626 & $<0.001$ & 0.644 & 0.207 & & \\
\hline \multicolumn{9}{|l|}{ Intensity } \\
\hline Light (1-99 epg) & 20 & 46 & 19 & 6 & 24 & 17 & 24 & 156 \\
\hline $\begin{array}{l}\text { Moderate (100-399 } \\
\text { epg) }\end{array}$ & 1 & 19 & 13 & 1 & 4 & 1 & 2 & 41 \\
\hline Heavy ( $\geq 400$ epg) & 0 & 7 & 2 & 0 & 1 & 1 & 1 & 12 \\
\hline
\end{tabular}

$\mathrm{N}=905$ Karima $\mathrm{N}=114$, Rurumi $\mathrm{N}=230$, Kasarani $\mathrm{N}=121$, Kirogo $\mathrm{N}=100$, Kamucege $\mathrm{N}=128$, Block $\mathrm{N}=105$, Gakungu $=107$ 
Table 4 Association between S. mansoni infection and demographic variables

\begin{tabular}{|c|c|c|c|c|}
\hline \multirow[t]{2}{*}{ Variables } & \multicolumn{2}{|c|}{ S. mansoni } & \multirow[t]{2}{*}{ OR $(95 \% \mathrm{Cl})$} & \multirow[t]{2}{*}{$P$-value } \\
\hline & Positive & Negative & & \\
\hline \multicolumn{5}{|l|}{ Sex } \\
\hline Female & $141(22.1)$ & 497(77.9) & REF & \\
\hline Male & $68(25.5)$ & 199(74.5) & $1.204(0.863-1.680)$ & 0.273 \\
\hline Total & 209 & 696 & & \\
\hline \multicolumn{5}{|l|}{ Age (years) } \\
\hline$>55$ & $36(26.1)$ & 102(73.9) & REF & \\
\hline $46-55$ & $36(24.2)$ & 113(75.8) & 0.903(0.529-1.540) & 0.707 \\
\hline $36-45$ & 53(19.3) & $221(80.7)$ & 0.679(0.419-1.102) & 0.116 \\
\hline $26-35$ & $69(25.7)$ & 199(74.3) & $0.982(0.615-1.569)$ & 0.941 \\
\hline$\leq 25$ & 15(19.7) & $61(80.3)$ & $0.697(0.353-1.376)$ & 0.297 \\
\hline Total & 209 & 696 & & \\
\hline \multicolumn{5}{|l|}{ Marital status } \\
\hline Single/Widow(er)/Divorced & $66(22.5)$ & $227(77.5)$ & REF & \\
\hline Married & $143(23.4)$ & 469(76.6) & 1.049(0.752-1.462) & 0.779 \\
\hline Total & 209 & 696 & & \\
\hline \multicolumn{5}{|l|}{ Religion } \\
\hline Others & $6(13.6)$ & 38(86.4) & REF & \\
\hline Christian & 203(23.6) & $658(76.4)$ & 1.954(0.814-4.688) & 0.127 \\
\hline Total & 209 & 696 & & \\
\hline \multicolumn{5}{|l|}{ Education } \\
\hline Secondary \& Post-secondary & $8(25.8)$ & $23(74.2)$ & REF & \\
\hline Secondary (Incomplete) & 28(18.7) & 122(81.3) & $0.660(0.267-1.628)$ & 0.365 \\
\hline Primary (Complete) & $82(22.0)$ & $291(78.0)$ & 0.810(0.349-1.878) & 0.623 \\
\hline Primary (Incomplete) & 78(27.9) & $202(72.1)$ & $1.110(0.476-2.587)$ & 0.809 \\
\hline No formal education & 13(18.3) & $58(81.7)$ & $0.644(0.236-1.759)$ & 0.389 \\
\hline Total & 209 & 696 & & \\
\hline \multicolumn{5}{|l|}{ Occupation } \\
\hline Farmer & $50(8.7)$ & $522(91.3)$ & REF & \\
\hline Business person & $64(52.0)$ & $59(48.0)$ & $1.248(0.845-1.843)$ & 0.265 \\
\hline Casual labourer & $68(43.3)$ & $89(56.7)$ & 0.879(0.616-1.255) & 0.477 \\
\hline Others & $27(50.9)$ & 26(49.1) & 1.195(0.680-2.098) & 0.535 \\
\hline Total & 209 & 696 & & \\
\hline \multicolumn{5}{|l|}{ Village } \\
\hline Gakungu & $27(25.2)$ & $80(74.8)$ & REF & \\
\hline Karima & $21(18.4)$ & 93(81.6) & $0.669(0.351-1.274)$ & 0.220 \\
\hline Rurumi & $72(31.3)$ & $158(68.7)$ & 1.350(0.805-2.266) & 0.255 \\
\hline Kasarani & $34(28.1)$ & $87(71.9)$ & 1.158(0.642-2.088) & 0.626 \\
\hline Kirogo & $7(7.0)$ & 93(93.0) & $0.223(0.092-0.540)$ & $<0.001$ \\
\hline Kamucege & $29(22.7)$ & $99(77.3)$ & 0.868(0.476-1.584) & 0.644 \\
\hline Block & 19(18.1) & 86(81.9) & 0.655(0.338-1.268) & 0.207 \\
\hline Total & 209 & 696 & & \\
\hline
\end{tabular}

$\mathrm{N}=905$ 


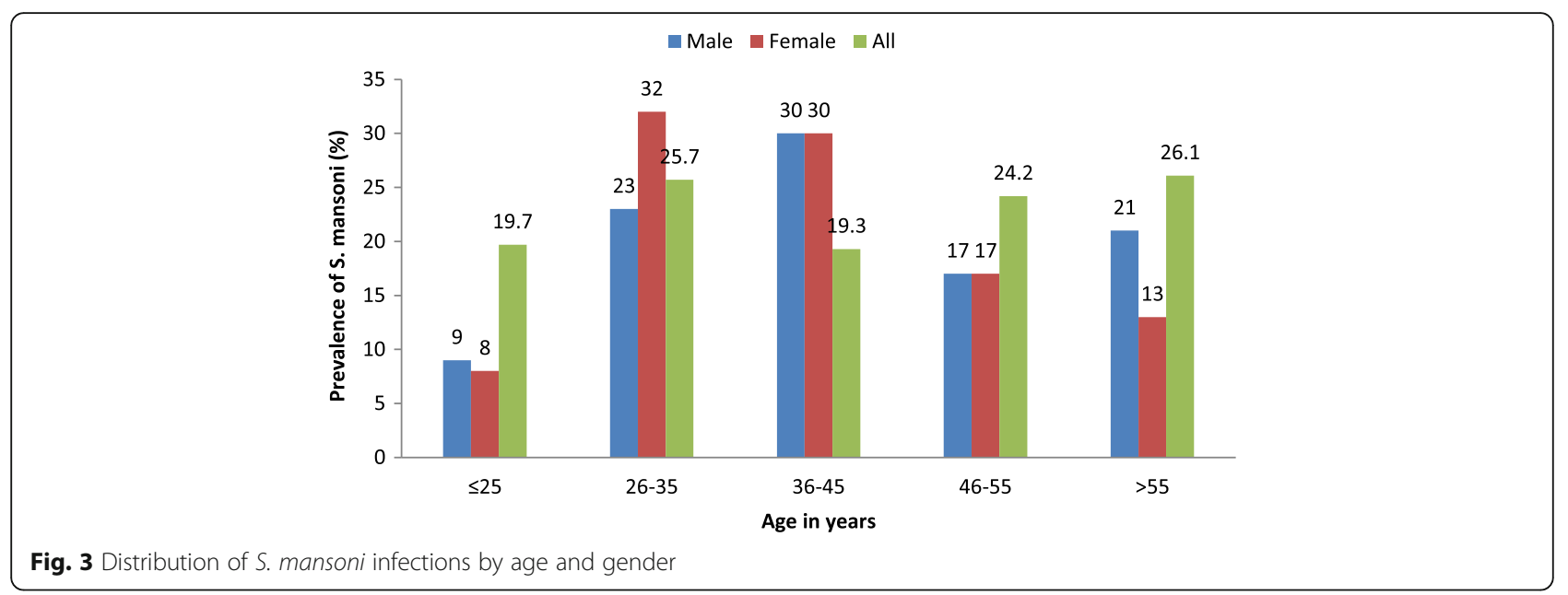

contrary (OR 0.623 (95\% CI 0.452-0.859). Other attributes of water consumed in the study households that were assessed in the study, including treating of water before use, time taken to fetch water and main person who fetches water for the household, did not show significant association with the infection.

A total of 678 (74.9\%) of the study households had access to an improved sanitation facility. Out of these, a total of 148 (21.8\%) household heads were infected with S.mansoni. Households with unimproved sanitation facilities were 227 (25.1\%), out of which 61 (26.9\%) household heads were infected with $S$. mansoni. However, there was no significant association between the type of sanitation facility (improved / unimproved) and S. mansoni infection ( $\mathrm{OR}=1.018$ (95\% CI: 0.705-1.469 $p=$ 0.926(Table 5).

\section{Discussion}

The control intervention for most NTDs including Schistosomiasis is largely focused on preventive chemotherapy which is implemented through school based programs. However, there has been growing interest to include the adult communities and WASH interventions in the preventive chemotherapy programs. The current study has demonstrated that S. mansoni is a public health problem among the population living in Mwea, Kirinyaga County. The S. mansoni prevalence recorded in this study $23.1 \%$ (95\% CI: $20.5-26.0 \%$ ) places the study area under the WHO classification of moderaterisk communities [41]. Majority of the infections reported in this study were of light intensity which is consistent with findings from Western Kenya [42] and also supports previous findings that most individuals in endemic areas excrete low number of eggs [43].

In areas of moderate schistosomiasis risk, WHO recommends preventive chemotherapy as a strategy for morbidity control that will help lessen the occurrence and severity of consequences of infection for risk groups including irrigation workers, fishermen and women of child bearing age [44]. This result therefore adds to the growing concern that the adult community needs to be included in schistosomiasis control programmes since they may provide an avenue for continued re- infection of the school going children who are usually targeted for treatment in the school-based deworming programmes. Similar observations have been made in previous studies $[6,45,46]$.

In this study, male participants were more at risk of infection with S. mansoni than female participants which is consistent with previous findings $[47,48]$. This could be explained by the fact that, in most communities, male are more exposed to frequent water contact partly due to their economic activities like farming. This has been observed in other studies [49-52]. Participants who were advanced in age ( $>55$ years) were the most affected with S. mansoni at $26.1 \%$. Schistosoma mansoni is a chronic infection which means that a person can live with the infections for a long time without seeking treatment. Similar findings have been reported elsewhere [9].

Majority of the households in the study had inadequate access to improved sources of water; however, there was no significant association between household water sources and $S$. mansoni infections. The national coverage for access to improved water in Kenyan rural areas stands at 59\% [53], while the global coverage as at 1990 was 76\% [38]. Previous studies have observed that, most countries where schistosomiasis is endemic have inadequate access to clean water sources $[1,24]$. Surface water from open water bodies such as rivers, streams and irrigation channels, was the most common source of water for majority of the study participants. This has previously been observed elsewhere by Tchuem Tchuenté et al. who noted that natural water bodies many of which are infested with snails and infective 
Table 5 - Association between S. mansoni infections, water and sanitation variables

\begin{tabular}{|c|c|c|c|c|}
\hline \multirow[t]{2}{*}{ Variables } & \multicolumn{2}{|l|}{ S. mansoni } & \multirow[t]{2}{*}{ OR $(95 \% \mathrm{Cl})$} & \multirow{2}{*}{$\begin{array}{l}P \text { - } \\
\text { value }\end{array}$} \\
\hline & Positive & $\overline{\text { Negative }}$ & & \\
\hline \multicolumn{5}{|l|}{ Source of water in the household } \\
\hline Unprotected dug well/Surface water & $180(23.5)$ & $585(76.5)$ & REF & \\
\hline Piped & $6(12.5)$ & $42(87.5)$ & $0.464(0.194-1.110)$ & 0.078 \\
\hline Borehole & $7(14.3)$ & $42(85.7)$ & $0.542(0.239-1.227)$ & 0.136 \\
\hline Protected dug well & $3(50.0)$ & $3(50.0)$ & $3.250(0.650-16.243)$ & 0.149 \\
\hline Rainwater collection & 10(31.3) & $22(68.8)$ & $1.477(0.687-3.178)$ & 0.315 \\
\hline Other & $3(60.0)$ & $2(40.0)$ & $4.875(0.808-29.403)$ & 0.056 \\
\hline Total & 209 & 696 & & \\
\hline \multicolumn{5}{|l|}{ Time taken to fetch water from the source } \\
\hline More than $30 \mathrm{~min}$ & $16(26.2)$ & 45(73.8) & REF & \\
\hline On premises & $64(22.4)$ & $222(77.6)$ & $1.112(0.463-2.672)$ & 0.812 \\
\hline Less than $30 \mathrm{~min}$ & 129(23.1) & $429(76.9)$ & $1.160(0.494-2.725)$ & 0.733 \\
\hline Total & 209 & 696 & & \\
\hline \multicolumn{5}{|l|}{ Satisfied with the water supply (source) } \\
\hline Not satisfied & 136(26.7) & $374(73.3)$ & REF & \\
\hline Satisfied & 73(18.5) & $322(81.5)$ & $0.623(0.452-0.859)$ & 0.004 \\
\hline Total & 209 & 696 & & \\
\hline \multicolumn{5}{|l|}{ Drinking water classification } \\
\hline Un improved & 182(23.7) & $585(76.3)$ & REF & \\
\hline Improved & 27(19.6) & $111(80.4)$ & $0.782(0.497-1.229)$ & 0.285 \\
\hline Total & 209 & 696 & & \\
\hline \multicolumn{5}{|l|}{ Toilet/Sanitation facility type } \\
\hline No facility & $1(7.1)$ & 13(92.9) & REF & \\
\hline VIP/simple pit latrine with floor/slab & 148(21.8) & $530(78.2)$ & $1.755(0.210-14.693)$ & 0.507 \\
\hline Pit latrine without floor/slab & $46(23.2)$ & 152(76.8) & $1.852(0.217-15.786)$ & 0.999 \\
\hline Other & 14(93.3) & $1(6.7)$ & $2.400(0.264-21.787)$ & 0.661 \\
\hline Total & 209 & 696 & & \\
\hline \multicolumn{5}{|l|}{ Toilet shared with other households } \\
\hline Not shared & 154(22.2) & $540(77.8)$ & REF & \\
\hline Shared & $54(27.4)$ & 143(72.6) & $1.149(0.791-1.668)$ & 0.466 \\
\hline Total & 208 & 683 & & \\
\hline \multicolumn{5}{|l|}{ Toilet in use } \\
\hline No & $6(66.7)$ & $3(33.3)$ & REF & \\
\hline Yes & $202(22.9)$ & $680(77.1)$ & $0.400(0.089-1.802)$ & 0.207 \\
\hline Total & 208 & 683 & & \\
\hline \multicolumn{5}{|l|}{ Presence of faeces on the floor } \\
\hline No & 163(23.2) & $541(76.8)$ & REF & \\
\hline Yes & $45(24.1)$ & 142(75.9) & $1.069(0.730-1.564)$ & 0.732 \\
\hline Total & 208 & 683 & & \\
\hline \multicolumn{5}{|l|}{ Household has child(ren) under 3 years } \\
\hline No & $161(22.4)$ & $558(77.6)$ & REF & \\
\hline Yes & $48(25.4)$ & 138(74.6) & $1.195(0.820-1.742)$ & 0.353 \\
\hline Total & 209 & 696 & & \\
\hline
\end{tabular}


Table 5 - Association between S. mansoni infections, water and sanitation variables (Continued)

\begin{tabular}{|c|c|c|c|c|}
\hline \multirow[t]{2}{*}{ Variables } & \multicolumn{2}{|c|}{ S. mansoni } & \multirow[t]{2}{*}{ OR $(95 \% \mathrm{Cl})$} & \multirow{2}{*}{$\begin{array}{l}P \text { - } \\
\text { value }\end{array}$} \\
\hline & Positive & Negative & & \\
\hline \multicolumn{5}{|c|}{ Disposal of faeces for children $<3$ years } \\
\hline Put/rinsed into toilet or latrine & $42(25.0)$ & 124(75.0) & REF & \\
\hline Child used toilet/latrine & $3(33.3)$ & $6(66.7)$ & $1.500(0.359-6.270)$ & 0.695 \\
\hline Other & $3(27.3)$ & $8(72.7)$ & $1.125(0.285-4.441)$ & 0.999 \\
\hline Total & 48 & 138 & & \\
\hline \multicolumn{5}{|l|}{ Sanitation facility type } \\
\hline Un-improved & $61(26.9)$ & 166(73.1) & REF & \\
\hline Improved & $148(21.8)$ & $530(78.2)$ & $1.018(0.705-1.469)$ & 0.926 \\
\hline Total & 209 & 696 & & \\
\hline
\end{tabular}

$\mathrm{N}=905+$ Disposal of faeces for children $<3$ years, $n=185$

schistosome cercariae are common sources for domestic water in most schistosomiasis endemic areas [54].

Usually people become infected with schistosomiasis when they come into contact with infested water and cercariae penetrate the skin. Schistosome eggs are then excreted in human faeces or urine and when they get into water bodies, miracidia which are released from the eggs in turn infects the snails, which release cercariae which penetrates human skin [1].

Households whose heads had access to piped water had the lowest infection with $S$. mansoni among those with improved water sources at $13 \%$. Infection was highest among those who utilized improved water from protected dug well at 50\%. The results further show that there was no significant association between household water sources and S. mansoni infection. Previous studies have reported strong association between access to improved water sources; with significantly less infection with $S$. mansoni [45, 55-57]. Another study linked lack of access to clean water sources to $47 \%$ population attribute 'able fraction (PAF) of schistosomiasis [58]. Improved water sources may not contain cercariae, but even so, its provision may not prevent all water contact with infested water. Therefore, when looking at the relationship between water and S. mansoni infection, there is need to also consider the environmental set up since areas under flood irrigation e.g. rice irrigation areas may be different from other areas.

Mwea is a rice irrigation scheme where people live in clustered villages which are surrounded by vast rice fields, and water from the rice drainage flows freely in to canals and streams which cuts across the villages, and thus even when a household has access to improved water sources, there could be high chances of them coming into contact with water from unimproved sources. Previous studies have alluded to this. Groups like irrigation workers and canal cleaners have suffered high exposure to infested water in the People's Republic of China [59, 60]. Another study in Brazil found out that people who crossed streams were at significantly higher risk of S. mansoni infection [61].

In regards to household access to sanitation facilities, the present study did not find an association between the type of sanitation facility (Improved or unimproved) with $S$. mansoni infections. This is in contrast to other findings which have reported significant lower odds of $S$. mansoni infection among people with access to adequate sanitation [57, 62]. In order to sustain transmission, a schistosome egg must enter freshwater to infect snail which will then release cercariae which infects people who come into contact with water [1]. For sanitation to be effective in controlling schistosomiasis, it should be able to contain fecal matter and urine hence preventing the schistosome eggs from hatching and thus ensuring that there are no miracidia to infect the snails. Studies have demonstrated that schistosome reproduces exponentially within the host snail, and therefore even small numbers of eggs entering freshwater may give rise to high risk of infection to people coming into contact with the water [63]. Studies have shown that even when high sanitation coverage levels are achieved, their use may still remain low $[64,65]$, due to various behavioral factors [66]. Open water bodies have been shown to be particularly attractive sites for open defecation [67]. The study area being a rice irrigation scheme, where sanitation facilities are not provided for in the farms, there are possibilities of open defecation when people are working in the farms. This has been demonstrated by Chimbari et al. [68].

We acknowledge that our sample selection process could be a potential source of bias since we used the households as unit of randomization and individuals as the units of study. We however used an effect of design of two for the sample size calculation which gave us a larger sample so as to minimize this bias. Secondly, we did not factor in data on possible 
behavioural factors such as open defecation which could also play a role in schistosomiasis transmission. Future studies may consider incorporating this aspect. Also, the study analysed single stool sample using the Kato Katz technique which might have missed light infections because of its poor sensitivity and day to day fluctuations in egg excretion [69]. Future population studies may enhance this by collecting stool samples for at least two consecutive days.

\section{Conclusion}

In conclusion, this study reaffirms that $S$. mansoni is still a public health problem among communities living in Kirinyaga County. The study also shows that individuals of all age groups are infected with S. mansoni and thus supports the call for inclusion of the adult community in targeted mass drug administration. There was inadequate access to improved water sources in the study area but adequate access to improved sanitation facilities. However, there was no significant association between $S$. mansoni infection with either access to improved water sources or sanitation facilities. The findings of this study add to the existing knowledge on the association between specific WASH components and Schistosoma mansoni infections in areas where rice irrigation farming is practiced. The study recommends further investigations on the association of schistosomiasis infections and hygiene in similar set ups.

\section{Additional file}

Additional file 1: Household questionnaire. (DOCX $26 \mathrm{~kb}$ )

\begin{abstract}
Abbreviations
CHWs: Community Health Workers; Cl: Confidence interval; DALYs: Disability Adjusted Life Years; Epg: Eggs per gram of faeces; ESACIPAC: Eastern \& Southern Africa Center of International Parasite Control; IQR: Interquartile range; JCA: Japan International Corporation Agency; JMP: Joint Monitoring Programme; KDHS: Kenya demographic and health surveys; KEMRI: Kenya medical research institute; MDA: Mass drug administration; MDG: Millennium development goals; MIRERC: Meru Univeristy of Science and Technology Institutional Research Ethics Research Committee; NTDs: Neglected tropical diseases; OR: Odds ratio; SBDP: School based deworming program; SERU: Scientific and ethical review unit; UNICEF: United Nations children's fund; VIP latrines: Ventilated improved latrines; WASH: Water sanitation and hygiene; WHO: World health organization
\end{abstract}

\section{Publisher's Note}

Springer Nature remains neutral with regard to jurisdictional claims in published maps and institutional affiliations.

\section{Acknowledgements}

The authors are sincerely grateful to all the staff of Eastern and Southern Africa Center of International Parasite Control (ESACIPA), Kirinyaga County Government, staff working in Kimbimbi sub county hospital laboratories and the residents of Karima, Rurumi, Kasarani, Gakungu, Kirogo, Kamucege and Block villages. Without them, this work would not have been possible.

\section{Protocol ethical approval}

Kenya Medical Research Institute (KEMRI), Scientific and Ethic Research Unit (SERU) Protocol Number: KEMRI/SERU/ESACIPAC/007/3326. Approval date October 31, 2016.

\section{Authors' contributions}

PMG, SK, and CM were involved in the study design, data collection and manuscript writing. CK, DM, JM carried out data collection, analysis and manuscript preparation. GM and HDM critically reviewed the manuscript and result interpretation. All authors read and approved the final manuscript.

\section{Funding}

The study was funded by Kenya Medical Research Institute (KEMRI) Internal Research Grants (IRG). The funder did not have any other role in the design of the study, collection, analysis, and interpretation of data and in writing of this manuscript.

\section{Availability of data and materials}

Please contact the corresponding author for data requests.

\section{Ethics approval and consent to participate}

Prior to the implementation of the study, ethical approvals were sought from the Scientific and Ethical Review Unit (SERU) of the Kenya Medical Research Institute (KEMRI), number (KEMRI/SERU/ESACIPAC/007/3326) and Meru University of Science and Technology Institutional Research Ethics Review Committee (MIRERC), number (MIRERC/001/2017), and the Health Management Team of Kirinyaga County. All the household heads participating in the study signed a written informed consent which had been translated into the local dialect. Those who could not read or write were asked to have an independent person as a witness who ensured that the study was clearly explained to them and guided them to give a thumb print on the consent form.

\section{Consent for publication}

Not applicable.

\section{Competing interests}

The authors declare that they have no competing interests.

\section{Author details}

${ }^{1}$ Eastern and Southern Africa Center for International Parasite Control (ESACIPAC), Kenya Medical Research Institute (KEMRI), P.O BOX 54840-00200, Nairobi, Kenya. ${ }^{2}$ School of Health Sciences, Meru University of Science and Technology, P.O BOX 972-60200, Meru, Kenya. ${ }^{3}$ London School of Tropical Medicine and Hygiene, Keppel St, Bloomsbury, London, WCIE 7HT, UK. ${ }^{4}$ School of Public Health, Pwani University, P.O BOX 195-80108, Mombasa, Kenya. ${ }^{5}$ Vectorborne diseases Control Unit, Ministry of Health, P.o box 86-10303, Wanguru, Kenya. ${ }^{6}$ Department of Medical Parasitology, School of Medicine, Catholic University of Health and Allied Sciences, P.O. Box 1464, Mwanza, Tanzania.

Received: 16 August 2018 Accepted: 17 May 2019

Published online: 07 June 2019

References

1. Colley DG, Bustinduy AL, Secor WE, King CH. Human schistosomiasis. Lancet. 2014;383:2253-64

2. Global Burden of Disease Study 2013 Collaborators. Global, regional, and national incidence, prevalence, and years lived with disability for 301 acute and chronic diseases and injuries in 188 countries, 1990-2013: a systematic analysis for the Global Burden of Disease Study 2013. Lancet. 2015; 386(9995):743-800.

3. Ezeamama $A E$, et al. Gaining and sustaining schistosomi-asis control: study protocol and baseline data prior to differenttreatment strategies infive African countries. BMC Infect Dis. 2016;16:229.

4. Huldah CS, Geoffrey M, Maurice O, Maurice RO, Pauline NM. Schistosoma haematobiumhotspots in South Nyanza, western Kenya: prevalence, distribution and co-endemicitywithSchistosoma mansoniand soiltransmitted helminths. Parasit Vectors. 2015;7:125.

5. GAHI (2010) Global Atlas of Helminth Infections. http://www. thiswormyworld.org. Accessed 22 Dec 2018. 
6. Mwandawiro CM, Nikolay B, Kihara JH, Ozier O, Mukoko DA, Mwanje MT, et al. Monitoring and evaluating the impact of national school-based deworming in Kenya: study design and baseline results. Parasit Vectors. 2013;6:198.

7. Hotez P, Fenwick A. Schistosomiasis in Africa: an emerging tragedy in our new global health decade. PLoS Negl Trop Dis. 2009;3(9):e485. https://doi. org/10.1371/journal.pntd.0000485 PMID: 19787054.

8. Woodhall DM, Wiegand RE, Wellman M, Matey E, Abudho B, Karanja DM, Mwinzi PM, Montgomery SP, Secor WE. Use of geospatial modeling to predict Schistosoma mansoni prevalence in Nyanza Province, Kenya. PLoS One. 2013;8:e71635.

9. Masaku J, Mutungi F, Gichuki P, Okoyo C, Njomo D, Njenga S. High prevalence of helminths infection and associated risk factors among adults living in a rural setting, Central Kenya: a crosssectional study. Trop Med Health. 2017:45:15. https://doi.org/10.1186/s41182-017-0055-8.

10. Kihara JH, Muhoho N, Njomo D, Mwobobia IK, Josyline K, et al. Drug efficacy of praziquantel and albendazole in school children in Mwea Division, Central Province, Kenya. Acta Trop. 2007;102:165-71.

11. Montresor A, Engels D, Chitsulo L, Bundy DA, Brooker S, et al. Development and validation of a 'tablet pole' for the administration of praziquantel in sub-Saharan Africa. Trans R Soc Trop Med Hyg. 2001;95:542-4 2.

12. King $\mathrm{CH}$, Dickman $\mathrm{K}$, Tisch DJ. Reassessment of the cost of chronic helmintic infection: a meta-analysis of disability-related outcomes in endemic schistosomiasis. Lancet. 2005;365:1561-9.

13. WHO. Accelerating work to overcome the global impact of neglected tropical diseases a roadmap for implementation. Geneva: World Health Organization; 2012.

14. Molyneux DH, Malecela MN. Neglected tropical diseases and the millennium development goals: why the "other diseases" matter: reality versus rhetoric. Parasit Vectors. 2011;4:234.

15. Doenhoff MJ, Hagan P, Cioli D, Southgate V, Pica-Mattoccia L. Praziquantel: its use in control of schistosomiasis in sub-Saharan Africa and current research needs. Parasitology. 2009;136:1825-35.

16. Campbell SJ, Savage GB, Gray DJ, Atkinson J-AM, Soares Magalhães RJ, Nery SV, et al. Water, sanitation, and hygiene (WASH): a critical component for sustainable soil-transmitted helminth and schistosomiasis control. PLoS Negl Trop Dis. 2014;8:e2651.

17. Clements ACA, Bosqué-Oliva E, Sacko M, Landouré A, Dembélé R, Mamadou Traoré $\mathrm{M}$, et al. A comparative study of the spatial distribution of schistosomiasis in Mali in 1984-1989 and 2004-2006. PLoS Negl Trop Dis. 2009;3:e431.

18. WHO. Helminth control in school-age children. Geneva: World Health Organization; 2011.

19. WHO. Accelerating work to overcome the global impact of neglected tropical diseases Da roadmap for implementation. Geneva: World Health Organization; 2012.

20. Grimes JE, Croll D, Harrison WE, Utzinger J, Freeman MC, Templeton MR. The roles of water, sanitation and hygiene in reducing schistosomiasis: a review. Parasit Vectors. 2015;8:156.

21. WHO. Helminth control in school age children: a guide for managers of control programmes. 2nd ed. Geneva: World Health Organization; 2011.

22. Bartram J, Cairncross S. Hygiene, sanitation, and water: forgotten foundations of health. PLoS Med. 2010;7:e1000367. https://doi.org/10.1371/ journal. pmed.1000367

23. Ferriman A. BMJ readers choose the "sanitary revolution" as greatest medical advance since 1840. BMJ. 2007. https://doi.org/10.1136/bmj.39097.611806.DB.

24. WHO, UNICEF. Progress on drinking water and sanitation - 2014 update Geneva: World Health Organization; 2014.

25. Secor WE. Water-based interventions for schistosomiasis control. Pathog Glob Health. 2014;108:246-54.

26. Kosinski KC, Adjei MN, Bosompem KM, Crocker JJ, Durant JL, et al. Effective control of Schistosoma haematobium infection in a Ghanaian community following installation of a water recreation area. PLoS Negl Trop Dis. 2012;6: e1709.

27. Water sanitation and hygiene for accelerating and sustaining progress on neglected tropical diseases A global strategy 2015-2020. Geneva: World Health Organization; 2015.

28. Freeman MC, Clasen T, Brooker SJ, Akoko DO, Rheingans R. The impact of a school-based hygiene, water quality and sanitation intervention on soiltransmitted helminth reinfection: a cluster-randomized trial. Am J TropMed Hyg. 2013;89:875-83.
29. Freemanm MC, Chard AN, Nikolay B, Garn V, Okoyo C, Kihara J, Njenga S, Pullan R, Brooker SJ, Mwandawiro CS. Associations between school- and household-level water, sanitation and hygiene conditions and soiltransmitted helminth infection among Kenyan school children. Parasit Vectors. 2015;8:412. https://doi.org/10.1186/s13071-015-1024-x.

30. Echazú A, Bonanno D, Juarez M, Cajal SP, Heredia V, Caropresi S, et al. Effect of poor access to water and sanitation as risk factors for soil-transmitted helminth infection: selectiveness by the infective route. PLOS Negl Trop Dis. 2015;9(9):e0004111. https://doi.org/10.1371/journal.pntd.0004111.

31. Strunz EC, Addiss DG, Stocks ME, Ogden S, Freeman MC. Water, sanitation hygiene, and soil-transmitted helminth infection: a systematic review and meta-analysis. PLoS Med. 2014;11(3):e1001620. https://doi.org/10.1371/ journal.pmed.1001620 PMID: 24667810.

32. Ziegelbauer K, Speich B, Mäusezahl D, Bos R, Keiser J, Utzinger J. Effect of sanitation on soil-transmitted helminth infection: systematic review and meta-analysis. PLoS Med. 2012;9(1):e1001162. 22291577. https://doi.org/10. 1371/journal.pmed.1001162.

33. Campbell SJ, Savage GB, Gray DJ, Atkinson J-AM, Soares Magalhães RJ, et al. Water, Sanitation, and hygiene (WASH): a critical component for sustainable soil-transmitted helminth and SchistosomiasisControl. PLoS Negl Trop Dis. 2014;8(4):e2651. https://doi.org/10.1371/journal.pntd.000265.

34. Kenya National Bureau of Statistics (KNBS). 2009 Population and Housing Census. Nairobi: KNBS; 2012.

35. Njiru JM, Muhoho N, Simbauni JA, Kabiru E. Effects of Soil- Transmitted Helminths and Schistosoma Species on Nutritional Status of Children in Mwea Irrigation Scheme, Kenya. JALSI. 2016;5(1):1-8 Article no.JALSI.25053.

36. Masaku J, Madigu N, Okoyo C, Njenga SM. Current status of Schistosoma mansoni and the factors associated with infection two years following mass drug administration programme among primary school children in Mwea irrigation scheme: a crosssectional study. BMC Public Health. 2015;15:739.

37. Fisher C. A study of schistosomiassis of Stanleyville district of the Belgian Congo. Trans R Soc Trop Med Hyg. 1999;1934(28):227-306.

38. JMP. Progress on sanitation and drinking water- 2015 update and MDG assessment, vol. 2015; 2015. Report No

39. Katz N, Chaves A, Pellegrino J. A simple device for quantitative stool thicksmear technique in schistosomiasis mansoni. Rev Inst Med Trop Sao Paulo. 1972;14:397-400.

40. Montresor A. Helminth control in school-age children: a guide for managers of control programmes: World Health Organization; 2002. http://www.who. int/iris/handle/10665/42473.

41. World Health Organization. Preventive chemotherapy in human helminthiasis coordinated use of antihelmintic drugs in control interventions: a manual for health professionals and programme managers. Geneva: World Health Organization; 2006.

42. Odiere M, Rawago F, Ombok M, Secor W, Karanja D, Mwinzi P, et al. High prevalence of schistosomiasis in Mbita and its adjacent islands of Lake Victoria, western Kenya. Parasit Vectors. 2012;5:278.

43. Butterworth AE, Sturrock RF, Ouma JH, Mbugua GG, Fulford AJC, Kariuki HC, et al. Comparison of different chemotherapy strategies against Schistosoma mansoni in Machako's district, Kenya. Effects on human infections and morbidity. Parasitology. 1991;103:339-55.

44. World Health Organization. Schistosomiasis Progress report (2001-2011) and strategic plan (2012-2020). Geneva: World Health Organization Press; 2013.

45. Lelo AE, Mburu DN, Magoma GN, Mungai BN, Kihara JH, Mwangi IN, et al. No apparent reduction in schistosome burden or genetic diversity following four years of school-based mass drug administration in mwea, Central Kenya, a heavy transmission area. PLoS Negl Trop Dis. 2014;8(10):e3221.

46. Anderson RM, Truscott JE, Pullan RL, Brooker SJ, Hollingsworth TD. How effective is school-based deworming for the community-wide control of soil-transmitted helminths? PLoS Negl Trop Dis. 2013;7:e2027. https://doi. org/10.1371/journal.pntd.0002027.

47. Donohue RE, Mashoto KO, Mubyazi GM, Madon S, Malecela MN, Michael E. Biosocial determinants of persistent schistosomiasis among schoolchildren in Tanzania despite repeated treatment. Trop Med Infect Dis. 2017;2:61.

48. Enk MJ, Lima ACL, Barros HDS, Massara CL, Coelho PMZ, Schall VT. Factors related to transmission of and infection with Schistosoma mansoni in a village in the south-eastern region of Brazil. Mem Inst Oswaldo Cruz. 2010;105:570-7.

49. Houmsou RS, Panda SM, Elkanah SO, Garba CL, Wama BE, Amuta EU, et al. Cross-sectional study and spatial distribution of schistosomiasis among children in northeastern Nigeria. Asian Pac J Trop Biomed. 2016;6(6):477-84. 
50. Calasans TAS, Souza GTR, Melo CM, Madi RR, Jeraldo VLS Socioenvironmental factors associated with Schistosoma mansoni infection and intermediate hosts in an urban area of northeastern Brazil. PLoS One. 2018;13(5):e0195519. https://doi.org/10.1371/journal.pone.0195519.

51. Dawaki S, Al-Mekhlafi HM, Ithol I, Ibrahim J, Abdulsalam AM, Ahmed A, et al. Prevalence and riskfactors of schistosomiasis among hausa communities in Kanostate, Nigeria. Rev.Inst.Med.Trop. 2016;58:11.36.

52. Sanya RE, Muhangi L, Nampijja M, Nannozi V, Nakawungu PK, Abayo E. Schistosoma mansoni and HIV infection in a Ugandan population with high HIV and helminth prevalence. Tropical Med Int Health. 2015;20(9):1201-8. https://doi.org/10.1111/tmi.12545 PMID: 25976017.

53. Kenya National Bureau of Statistics (KNBS) and ICF Macro. Kenya Demographic and Health Survey 2014. Calverton: KNBS and ICF Macro; 2014.

54. Tchuenté TLA, Rollinson D, Stothard RJ, Molyneux D, et al. Moving from control to elimination of schistosomiasis in sub-Saharan Africa: time to change and adapt strategies. Infectious Diseases of Poverty. 2017;6:42. https://doi.org/10.1186/s40249-017-0256-8.

55. Nagi S, Chadeka EA, Sunahara T, Mutungi F, Dan Justin YK, et al. Risk factors and spatial distribution of Schistosoma mansoni infection among primary school children in Mbita District, Western Kenya. PLoS Negl Trop Dis. 2014 8(7):e2991. https://doi.org/10.1371/journal.pntd.0002991 PMID: 25058653.

56. Meurs L, Mbow M, Boon N, Van den Broeck F, Vereecken K, Dieye TN, Abatih E, Huyse T, Mboup S, Polman K. Micro-geographical heterogeneity in Schistosoma mansoni and S. haematobium infection and morbidity in a coendemic Community in Northern Senegal. PLoS Negl Trop Dis. 2013;7:e2608 pmid:24386499.

57. Grimes JET, Croll D, Harrison WE, Utzinger J, Freeman MC, Templeton MR. The relationship between water, sanitation and schistosomiasis: a systematic review and meta-analysis. PLoS Negl Trop Dis. 2014;8:e3296.

58. Soares Magalhaes RJ, Barnett AG, Clements AC. Geographical analysis of the role of water supply and sanitation in the risk of helminth infections of children in West Africa. Proc Natl Acad Sci U S A. 2011;108:20084-9.

59. Song $Y$, Xiao S, Wu W, Zhang S, Xie H, Xu X, et al. Preventive effect of artemether on schistosome infection. Chin Med J. 1998;111:123-7.

60. Utzinger J, Xiao SH, N'Goran EK, Bergquist R, Tanner M. The potential of artemether for the control of schistosomiasis. Int J Parasitol. 2001;31:1549-62.

61. Massara CL, Peixoto SV, Da Silva BH, Enk MJ, Dos Santos CO, Schall V. Factors associated with schistosomiasis mansoni in a population from the municipality of Jaboticatubas, state of Minas Gerais, Brazil. Mem Inst Oswaldo Cruz. 2004;99:127-34

62. Freeman MC, Garn JV, Sclar GD, Boisson S, Medlicott K, Alexander KT, et al. Thomas F. Clasen: the impact of sanitation on infectious disease and nutritional status: a systematic review and meta-analysis. Int J Hyg Environ Health. 2017:220:928-49.

63. Ayad N. A short review of the epidemiology of schistosomiasis in Africa. Egypt J Bilharz. 1974;1:9-27.

64. Barnard S, Routray P, Majorin F, Peletz R, Boisson S, Sinha A, Clasen T. Impact of Indian Total sanitation campaign on latrine coverage and use: across-sectional study in Orissa three years following programmeimplementation. PLoS One. 2013;8:e71438.

65. Montgomery MA, Desai MM, Elimelech M. Assessment of latrine use and quality and association with risk of trachoma in rural Tanzania. Trans R Soc Trop Med Hyg. 2010;104(4):283-9.

66. Routray P, Schmidt WP, Boisson S, Clasen T, Jenkins MW. Socio-cultural and behavioural factors constraining latrine adoption in ruralcoastal Odisha: an exploratory qualitative study. BMC Public Health. 2015;15:880.

67. Tayo MA, Pugh RN, Malumfashi BAK. Endemic diseases research project, XI. Water-contact activities in the schistosomiasis study area. Ann Trop Med Parasitol. 1980;74:347-54

68. Chimbari M, Ndlela B, Nyati Z, Thomson A, Chandiwana SK, Bolton P. Bilharzia in a small irrigation community: an assessment of water and toilet usage. Cent Afr J Med. 1992;38:451-8.

69. Booth M, Vounatsou P, N'Goran EK, Tanner M, Utzinger J. The influence of sampling effort and the performance of the Kato-Katz technique in diagnosing Schistosoma mansoni and hookworm co-infections in rural cote d'Ivoire. Parasitology. 2003;127:525-31.

\section{Ready to submit your research? Choose BMC and benefit from:}

- fast, convenient online submission

- thorough peer review by experienced researchers in your field

- rapid publication on acceptance

- support for research data, including large and complex data types

- gold Open Access which fosters wider collaboration and increased citations

- maximum visibility for your research: over $100 \mathrm{M}$ website views per year

At BMC, research is always in progress.

Learn more biomedcentral.com/submissions 